\title{
Acute Renal Failure in Association with Community-Acquired Clostridium difficile Infection and McKittrick-Wheelock Syndrome
}

\author{
Robert M. Learney ${ }^{a}$ Paul Ziprin ${ }^{a}$ Pauline A. Swift ${ }^{b}$ \\ Omar D. Faiz

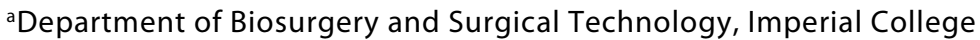 \\ London, St Mary's Hospital, London, and 'bepartment of Renal Medicine \\ and Transplantation, Epsom and St Helier University Hospitals NHS Trust, \\ Carshalton, UK
}

\section{Key Words}

Acute kidney failure $\cdot$ Haemofiltration $\cdot$ Clostridium difficile $\cdot$ McKittrick-Wheelock syndrome Villous adenoma

\begin{abstract}
We report the case of a 65-year-old Caucasian woman who experienced two separate episodes of acute renal failure within an 18-month period, both requiring emergency admission and complicated treatment. Each episode was precipitated by hypovolaemia from intestinal fluid losses, but from two rare and independent pathologies. Her first admission was attributed to community-acquired Clostridium difficile-associated diarrhoea (CDAD) and was treated in the intensive therapy unit. She returned 18 months later with volume depletion and electrolyte disturbances, but on this occasion a giant hypersecretory villous adenoma of the rectum (McKittrick-Wheelock syndrome) was diagnosed following initial abnormal findings on digital rectal examination by a junior physician. Unlike hospital-acquired C. difficile, community-acquired infection is not common, although increasing numbers are being reported. Whilst community-acquired CDAD can be severe, it rarely causes acute renal failure. This case report highlights the pathological mechanisms whereby C. difficile toxin and hypersecretory villous adenoma of the rectum can predispose to acute renal failure, as well as the values of thorough clinical examination in the emergency room, and early communication with intensivist colleagues in dire situations.
\end{abstract}




\section{Introduction}

Clostridium difficile-associated diarrhoea (CDAD) represents the leading cause of nosocomial diarrhoea in Europe and North America [1,2]. It occurs most frequently in the elderly, immunocompromised or long-term care residents, and in association with broad-spectrum antibiotic use. However, there are increasingly numerous reports of community-acquired $\operatorname{CDAD}[2,3]$, occurring in individuals who have had no contact with a healthcare facility in the preceding 12 weeks [2]. It has almost certainly been underreported and is increasingly recognised as an emerging problem. A recent United Kingdom-based study demonstrated a $2.1 \%$ prevalence of toxin positivity in community-acquired diarrhoeal samples [4]. The toxins of $C$. difficile have also been found in 3-5\% of faecal specimens from asymptomatic members of the population, making it difficult to ascertain the true prevalence of community-acquired CDAD $[2,4,5]$. Acute renal failure (ARF) is common in the hospital setting, particularly in the elderly and in response to hypovolaemia, but is only rarely described as a direct result of CDAD [3].

McKittrick-Wheelock syndrome was originally described in 1954 [6] and has been reported in the literature on fewer than 50 occasions since. The syndrome encompasses a triad of (i) profound volume and electrolyte depletion secondary to (ii) hypersecretory mucous diarrhoea arising from (iii) a giant villous adenoma of the rectum or sigmoid colon.

In this report we describe the clinical presentations and outcome of a patient who suffered two separate episodes of ARF, with complete functional recovery in the interim, arising from these two rare and independent colonic pathologies. A brief review of CDAD and McKittrick-Wheelock syndrome is also presented.

\section{Case Report}

In July 2007, a 65-year-old obese Caucasian British woman, with a family history of colorectal carcinoma (mother and grandmother), was admitted acutely to hospital. She reported 2 weeks of general malaise and had stopped all oral intake over the prior $48 \mathrm{~h}$. She described $24 \mathrm{~h}$ of vomiting, syncopal episodes and double incontinence of profuse brown liquid faeces and offensive urine.

She presented confused and disoriented with extensive bruises covering her arms and torso. She was hypothermic and severely shocked. Her blood results indicated sepsis, hypokalaemic metabolic acidosis, salt and water depletion and ARF (table 1). She was resuscitated with intravenous fluids, administered intravenous gentamicin and meropenem and immediately taken to the intensive therapy unit where she remained on inotropic support (dobutamine) and haemofiltration for 3 days. Renal ultrasound and an autoimmune screen were reported as normal. Urinalysis revealed only hyaline casts. A blood film demonstrated leukopaenia, large platelets without fragmentation and toxic granulation of neutrophils, consistent with an infective aetiology. There was no evidence of haemolysis or a microangiopathic process. Skin biopsies of the bruises were consistent with uraemic platelet dysfunction.

After $48 \mathrm{~h}$ on the intensive therapy unit, a sample of the patient's diarrhoea taken on initial arrival at hospital confirmed the presence of $C$. difficile toxin (Premier ${ }^{\mathrm{TM}}$ Toxins A and B ELISA, Meridian Bioscience Inc.). After confirming with the patient's general practitioner that there had been no recent exposure to antibiotics, she was diagnosed with community-acquired C. difficile infection. Treatment was changed to intravenous metronidazole and oral vancomycin and the other antibiotics were discontinued. After 1 week she was transferred to a medical ward. All antibiotics were discontinued by day 15, after her diarrhoea had stopped. She returned home 2 days later with a normal creatinine of $89 \mu \mathrm{mol} / \mathrm{l}$ and a urea of $5.8 \mathrm{mmol} / \mathrm{l}$. 
In November 2008, the patient returned with a shorter 48-hour history of vomiting, anuria and falls. Initial assessment found her in better condition than when she had originally presented in July 2007. She was in ARF, however without evidence of circulatory shock, sepsis or acidaemia (table 1). On this occasion she revealed that she had been producing frequent, clear mucus stools for an indeterminate number of weeks. Again, there was no preceding history of antibiotic use, but stool samples were negative for $C$. difficile toxin. Digital rectal examination by a junior doctor revealed an unusual spongy feel to the wall of the rectum. This was therefore followed by flexible sigmoidoscopy and magnetic resonance imaging to discover an extensive, circumferential soft fleshy lesion, carpeting $90 \%$ of the rectum from $2 \mathrm{~cm}$ above the anal verge to a depth of $12 \mathrm{~cm}$ ( $\underline{\text { fig. }}$ 1). Biopsy confirmed a non-malignant, highly secretory villous adenoma.

Initial management with intravenous fluid and electrolyte replacement returned her renal function to baseline levels within $48 \mathrm{~h}$. Definitive treatment, however, required surgical resection of the lesion. Following pre-operative counseling the patient elected non-restorative surgery and underwent laparoscopically-assisted abdomino-perineal excision of the rectum, as the extent of the tumour made it unamenable to local resection. The patient unfortunately suffered postoperative adhesional bowel obstruction (a small bowel loop adherent within the pelvis) necessitating re-intervention 4 weeks later in the form of an ileocaecal resection and double-barrelled ileostomy-colonic mucus fistula formation. She underwent successful stoma reversal 6 months later and remains well.

\section{Discussion}

Approximately 8 litres of secretions and additional fluids pass through the gastrointestinal tract per day, with less than $100 \mathrm{ml}$ eventually entering the faeces. The majority of resorption occurs in the colon. Alterations to colonic epithelial permeability, transit time, or intestinal content may destabilise this balance towards net loss. Severe or prolonged diarrhoeal illnesses can cause excessive depletion of salt and water from the gastrointestinal tract, leading to hypovolaemia, renal hypoperfusion and acute renal injury. The biochemical picture is usually one of hyperchloraemic metabolic acidosis with a normal anion gap, as there is a primary loss of bicarbonate from the gastrointestinal tract, with a compensatory hyperchloraemia [7]. In contrast, villous adenomas produce a secretory mucous diarrhoea that contains large amounts of potassium, sodium and chloride so that the classical clinical picture is one of hypokalaemic, hypochloraemic metabolic acidosis with a high anion gap $[8,9]$.

Our patient presented on both occasions with ARF, hyponatraemia and profound hypovolaemia requiring urgent fluid and electrolyte resuscitation, which is fundamental to successful treatment. Unfortunately the serum chloride and anion gap were not measured during either admission, which might have been helpful in formulating a differential diagnosis [7].

Although her rectal adenoma may well have been present and contributing to the intestinal discharge at her first presentation, given the clinical, serological and microbiological findings at the time, on balance of probabilities this was most likely a near-fatal manifestation of severe community-acquired CDAD. Community-acquired $\mathrm{CDAD}$ is more likely to occur in elderly patients with certain co-morbidities and risk factors (table 2) [10].

Clinical infection with C. difficile is almost always associated with initial disruption of the colonic microflora by broad-spectrum antibiotics $[3,4,11]$. Then follows the expression of at least two major toxins - toxins ' $A$ ' and 'B' $[2,11]$. The latter irreversibly glycosylates members of the Ras family of small GTPases, causing degradation of the actin cytoskeleton and disruption of epithelial tight junctions [11]. The colonic epithelium 
becomes inflamed and begins to lose salt and water, resulting in a profuse diarrhoea. It follows that a prolonged episode of diarrhoea would eventually result in systemic losses of salt and water, and thus hypovolaemic renal failure. Interestingly however, there are only 4 reports of this in the literature [3].

Despite its 'B' toxin modifying small GTPases involved in transcriptional regulation, cellular proliferation and apoptosis [11], there are no reports of $C$. difficile infection promoting adenomatous transformation of the colonic epithelium such as would link our patient's two pathologies. Her second presentation was consistent with the syndrome originally described by McKittrick and Wheelock [6] as evidenced by the extensive hypersecretory rectal adenoma.

To effect significant volume loss, the adenoma underlying McKittrick-Wheelock syndrome must measure some $7-18 \mathrm{~cm}$ in greatest dimension and cover a large percentage of the mucosal surface of the rectum or sigmoid colon [12], as more proximal adenomas may still allow for sufficient reabsorption of effluent $[12,13]$. The rarity of the syndrome is therefore explained by autopsy studies which have demonstrated that only $13-16 \%$ of villous adenomas reach $>2 \mathrm{~cm}$ in diameter [9], of which only $3 \%$ are secretory [14]. With regards to clinical management, the high rate of malignant transformation in large villous adenomas $[9,13]$, and mortality attached to untreated McKittrick-Wheelock syndrome $[9,13]$, suggests that pharmacological control of volume loss by the potent COX inhibitor indomethacin should only be considered as a temporising measure until the patient is stabilised for definitive surgical resection $[9,12,14]$. Our patient has done well following rectal excision, without any lasting evidence of renal impairment or further episodes of ARF.

In summary, we have described two episodes of ARF resulting from two uncommon and independent colorectal pathologies in order to highlight their importance when considering the differentials of ARF in diarrhoeal disease.

\section{Disclosure Statement}

There are no competing interests. 
Table 1. Blood results and vital signs

\begin{tabular}{|c|c|c|c|}
\hline Parameter & Reference range for women & July 2007 & November 2008 \\
\hline $\mathrm{Hb}, \mathrm{g} / \mathrm{dl}$ & $11.5-15.2$ & 18.0 & 14.4 \\
\hline WCC, $\times 10^{9} / 1$ & $3.9-11$ & 22.8 & 10.4 \\
\hline Platelets, $\times 10^{9} / 1$ & $147-397$ & 451 & 445 \\
\hline Haematocrit, \% & $36-46$ & 51.2 & 41.0 \\
\hline $\mathrm{pH}$ & $7.340-7.450$ & 7.300 & 7.492 \\
\hline $\mathrm{HCO}_{3}, \mathrm{mmol} / \mathrm{l}$ & $18-23$ & 11.2 & 23.3 \\
\hline Base excess, mEq/l & -2.0 to +2.0 & -15.2 & +1.0 \\
\hline Lactate, $\mathrm{mmol} / \mathrm{l}$ & $0.5-1.6$ & 4.32 & - \\
\hline $\mathrm{Na}^{+}, \mathrm{mmol} / \mathrm{l}$ & $135-145$ & 116 & 122 \\
\hline $\mathrm{K}^{+}, \mathrm{mmol} / \mathrm{l}$ & $3.5-5.3$ & 4.9 & 2.5 \\
\hline Urea, mmol/l & $2.5-6.6$ & 100 & 78 \\
\hline Creatinine, $\mu \mathrm{mol} / \mathrm{l}$ & $60-125$ & 966 & 611 \\
\hline Chloride, $\mathrm{mmol} / \mathrm{l}$ & $95-105$ & - & - \\
\hline Glucose, $\mathrm{mmol} / \mathrm{l}$ & $3.0-5.4$ & 10.2 & - \\
\hline Temperature, ${ }^{\circ} \mathrm{C}$ & & 35.4 & 37.0 \\
\hline Heart rate & & 130 & 71 \\
\hline Blood pressure, $\mathrm{mm} \mathrm{Hg}$ & & $70 / 35$ & $105 / 70$ \\
\hline $\mathrm{sO}_{2}$ (on air), $\%$ & & 75 & 95 \\
\hline
\end{tabular}

Abnormal results in bold.

Table 2. Risk factors for community-acquired C. difficile infection (after Dial et al. 2006 [10])

\begin{tabular}{|c|c|c|c|c|c|}
\hline Gastrointestinal & $\begin{array}{l}\text { Adjusted OR } \\
(95 \% \mathrm{CI})\end{array}$ & Medications & $\begin{array}{l}\text { Adjusted OR } \\
(95 \% \text { CI })\end{array}$ & Others & $\begin{array}{l}\text { Adjusted OR } \\
(95 \% \text { CI })\end{array}$ \\
\hline IBD & $46.1(14.5-146.7)$ & Antibiotics & $8.2(6.1-11.0)$ & Leukaemia/lymphoma & $10.3(1.3-81.5)$ \\
\hline Pernicious anaemia & $6.0(0.2-149.9)$ & Proton pump inhibitors & $3.5(2.3-5.2)$ & MRSA & $8.9(1.7-46.6)$ \\
\hline Peptic ulcer disease & $2.9(0.4-1.9)$ & & & Renal failure (inc. dialysis) & $6.2(2.7-13.9)$ \\
\hline Diverticular disease & $1.5(0.5-4.4)$ & & & Solid tumours & $4.9(1.5-16.5)$ \\
\hline
\end{tabular}

$\mathrm{IBD}=$ Inflammatory bowel disease. 


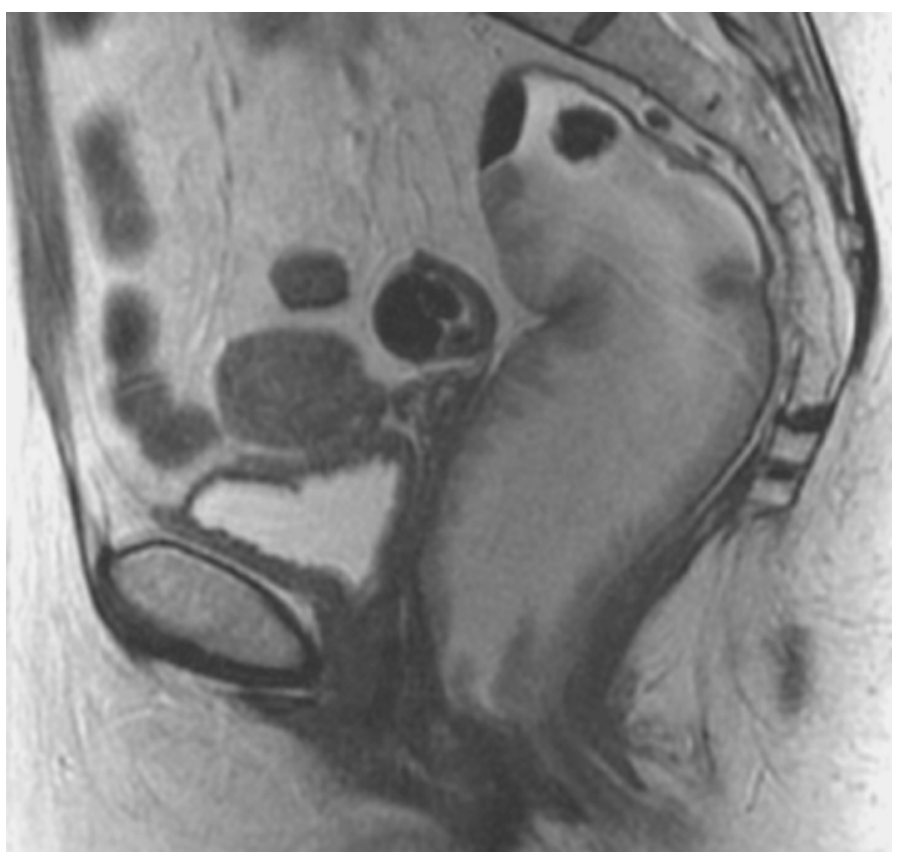

Fig. 1. Sagittal mid-rectal MR image demonstrating the extent of the superficial villous adenoma which led to McKittrick-Wheelock syndrome in our patient. It covers nearly the entirety of the patient's rectum from $2 \mathrm{~cm}$ above the anal verge to a depth of $12 \mathrm{~cm}$. 


\begin{tabular}{|c|c|c|c|}
\hline $\begin{array}{r}\text { Case Reports in } \\
\text { Gastroenterology }\end{array}$ & $\begin{array}{l}\text { Case Rep Gastroenterol 2011;5:438-444 } \\
\text { DOI: 10.1159/000330478 }\end{array}$ & $\begin{array}{l}\text { Published online: } \\
\text { August 18, } 2011\end{array}$ & $\begin{array}{l}\text { @ } 2011 \text { S. Karger AG, Basel } \\
\text { ISSN 1662-0631 } \\
\text { www.karger.com/crg }\end{array}$ \\
\hline
\end{tabular}

\section{References}

1 Song X, Bartlett JG, Speck K, et al: Rising economic impact of Clostridium difficile-associated disease in adult hospitalized patient population. Infect Control Hosp Epidemiol 2008;29:823-828.

$\longrightarrow 2$ Kuijpur EJ, Coignard B, Tull P: Emergence of Clostridium difficile-associated disease in North America and Europe. Clin Microbiol Infect 2006;12:2-18.

3 Arrich J, Sodeck GH, Sengolge G, et al: Clostridium difficile causing acute renal failure: Case presentation and review. World J Gastroenterol 2005;11:1245-1247.

$\checkmark 4$ Wilcox MH, Mooney L, Bendall R, et al: A case-control study of community-associated Clostridium difficile infection. J Antimicrob Chemother 2008;62:388-396.

5 Rivera EV, Woods S: Prevalence of asymptomatic Clostridium difficile colonisation in a nursing home population: a cross-sectional study. J Gend Specif Med 2003;6:27-30.

6 McKittrick LS, Wheelock FC Jr: Carcinoma of the colon. 1954. Dis Colon Rectum 1997;40:1494-1495.

7 Walmsley RN, White GH: Normal 'anion gap' (hyperchloremic) acidosis. Clin Chem 1985;31:309-313.

8 Winstanley V, Little MA, Wadsworth C, et al: The McKittrick-Wheelock syndrome: a case of acute renal failure due to neoplastic cholera. Ren Fail 2008;30:469-473.

-9 Popescu A, Orban-Schiopu AM, Becheanu G, et al: McKittrick-Wheelock syndrome - a rare cause of acute renal failure. Rom J Gastroenterol 2005;14:63-66.

10 Dial S, Delaney JAC, Schneider V, et al: Proton pump inhibitor use and risk of community-acquired Clostridium difficile-asociate disease defined by prescription of oral vancomycin therapy. CMAJ 2006;175: 745-748.

11 Voth DE, Ballard JD: Clostridium difficile toxins: mechanism of action and role in disease. Clin Microbiol Rev 2005; 18:247-263.

12 Older J, Older P, Colker J, et al: Secretory villous adenomas that cause depletion syndrome. Arch Intern Med 1999;159:879-880.

13 Yağmurdur MC, Alevli F, Gür G, et al: A giant villous adenoma case mimicking right colon carcinoma. Turk J Gastroenterol 2004;15:270-273.

14 Targarona EM, Hernandez PM, Balague C, et al: McKittrick-Wheelock syndrome treated by laparoscopy: report of 3 cases. Surg Laparosc Endosc Percutan Tech 2008;18:536-538.

Author contributions: R.M. Learney wrote the paper; P. Ziprin, O.D. Faiz and P.A. Swift contributed specialist information and analysis. All authors reviewed and approved the final paper. 